\title{
The Educational Value of Cooperative Education
}

\author{
${ }^{1}$ WANG Zulin \\ School of Education \\ Huazhong University of Science and Technology \\ Wuhan , China \\ E-mail: wangzulin1984@163.com
}

\author{
${ }^{2}$ HUANG Yiwu* \\ Research Institute for University Development \\ Yangtze University \\ Jingzhou, China \\ E-mail: 1833317010@qq.com \\ *Corresponsive Author
}

\begin{abstract}
Cooperative education is a kind of work-integrated learning activity that combines the students' learning in classroom into practice in society, it is the innovation of educational ideology and talents-cultivating model, it has become the tendency of higher education in the world. The educational value of cooperative education focus on the students development that are the improvement of students' comprehensive quality, the promotion of students' academic development and professional performance, so the quality of talents cultivating can be improved. The purpose of this study is to expose the educational value of cooperative education based on the literature review.
\end{abstract}

Keywords-cooperative education; educational value; student development

\section{INTRODUCTION}

Educational quality and students' employment are the vital task of university during the period of mass higher education. The college student should mast the professional knowledge and put it into practice. The combination of theoretical knowledge and vocational skills is useful to strengthen the learning objective and positivity, which helps students to learn to be recognitory, to learn to do , to learn to study and to learn to live. What educational model can satisfy with this requirements? The cooperative education can match this requirement and it has become the higher education tendency in the world. It involves university students undertaking full-time paid and discipline-related employment as a structured part of their study.It provides learning opportunities for students to integrate their work and their academic experiences. Such opportunities can lead to deep-level learning, whereby students engage in and interact with the learning material integrated into their knowledge and personal understanding. The cooperation education meets with the developmental needs of education and human s. It is also called work integrated learning in most countries today. In China, its name has been varied from cooperative education, the cooperation of industry and academy and the educational cooperation of industry-academy-research. The changes of the names aim to stress on the cooperator, but the original aim of cooperative education is to cultivate the qualified talents. In knowledge times, the cooperative contents and the cooperators are diversified, industry- academy-research can not illustrate them clearly and wholly, the concepts of the names is misunderstood easily, so the cooperative education is a proper name and can be abbreviated for co-op as the following given.. Co-op takes advantage of recourses inside and outside of university, helping students to put the theory into practice. It covers the shortage of the practical education of university and promotes the mutual interaction between university and society. Most studies of co-op pays attention to cooperative models, systems, policies, laws, case studies and other topics, but shortage of theory analysis and educational value research. The implication of educational value of co-op from the value perspective is beneficial to reasonable analysis of co-op and provide with theoretical guide for its practice.

\section{DEFINITION OF COOPERATIVE EDUCATION}

The co-op was explored and practiced by professor Herman Schneider in USA in 1906. When he was a student, he took part-time job in coal mine and factory, he felt the experimental learning was significant to his knowledge absorbing in classroom and the improvement of personal quality, practice-based knowledge can not be learned in university. Based on this idea, he put forward the program that students learn in school in certain time and work outside school in certain time under the cooperation of school and industry, the work reward can support the tuition. This program is called cooperative education and has become popular in the world. The definition of co-op is various in history. The Declaration of Cooperative Education in American Vocational Association in 1946 defined that co-op is a kind of educational model which combines the theoretical learning with the real-world work experiences, making the effectiveness of teaching in class. The World Association for Cooperative Education in 2001 explained that it combines the classroom study with the experiential learning and put the theory into work practice related to the theory and close to the real workplace and get reward, take the challenge and real perception into classroom, it promotes analysis and thinking. The Canadian Association for Cooperative Education points out that it is a form of program that combines the theoretical learning with the job post in workplace, it takes turns between professional learning in school and work practices in business, industry, government and the other field of social service. ${ }^{[1]}$ The co-op was agreed 
to be called"work-integrated learning” at the council meeting of World Association Cooperative Education in 2003. It is also called work-based learning or experimental learning in some countries, the work experiences is stressed.

The above definitions generally stress on the cooperation and wok integrated learning, it is a kind of educational model, the work experiences related to vocation and professional learning. In China, its typical definition is that it aims to train students with overall quality, comprehensive ability and competitive employment to meet different requirements of employer using two educational resources and environments (university and society) by classroom study and work experiences, which is a kind of educational model to cultivate students with overall quality and innovative ability. ${ }^{[2]}$ One scholar points out that it is an educational form participated by academic institution, society and the students using two different atmospheres to give the students to have the work experiences related to academic study on campus in turns, finally to improve educational quality and employment rate. But the concept of society in this definition is unclear and the academic institution and students belong to society, so the employer can take place of the society. In authors' opinion, the co-op is a kind of educational model using two different environments and resources under the cooperation of academic institution, employer and students to cultivate students with higher quality meeting with the employer's satisfaction by work-integrated learning.

\section{UNDERSTANDINGS OF COOPERATIVE EDUCATION}

The co-op aims to cultivate talents with higher quality and improve employment competition. Its basic form is work integrated learning its effectiveness depends on the positive cooperation of employer, university and students, and the mutual benefits. It is close to talents market and workplace compared with the traditional education model, using the recourses inside and outside of university to educate students. It is not the unique model of education, the forms and types of co-op is diversified. It is properly used to train various kinds of talents not only the skill-based and operation-based but also to educate students with innovative spirit and quality, which depends on cooperative aims, conditions and environment among cooperators. For instance, the co-op is widely used and developed in community college, technical college, undergraduate or research university in USA. The cooperative was successful in chemistry and physics and extended to other disciplines considered to be difficultly applied at Viatorial University in Canada in 1975.

Cooperative education is different from internships in China, their differences embody in aim, students' role, reward and work time. The work experiences should be enough and relevant to the academic learning, the students are governed and supervised by the employment units and get rewards from the employers. The co-op belongs to industry-university-institution cooperation that is a large scopes and stresses on research cooperation and the building of strategic alliances besides talents cultivating. Co-op is a kind of modern educational forms or models. It is an effective way to collaborate education with work to cultivate talents with integrated development. It comes out based on the historical development of education and theoretical foundation related to the social background and the development of productivity level in its history. It has become the promising model or tendency of higher education in the future. It collaborates the development of society and people, which obeys the educational laws and rules. However, the co-op is not universal, it has its own limitations. It is widely used to train students with skillsdeveloped quality. Of course, it can educate innovative talents depending on the contents and forms of cooperation.

The obvious distinction of co-op is its collaboration of campus study and work experiences out $\mathrm{f}$ campus related to the futural career and professional learning, which is founded at the background of modern science and technology to meet the needs of human's survival and career development in market economy, so the co-op has the characteristics of modernity, vocation, marketization and popularity. ${ }^{[3]}$ It breaks through the traditional higher education model and is the innovation of educational ideology and model. It has the distinctive vale for training students with fully developed. It provides students with a new cultural environment different from university culture, signifying experience and practice, collaborating theory into practice, which matches with the needs of human's growth.

\section{EdUCATIONAL VALUE OF COOPERATIVE EDUCATION}

Value comes from the practical interaction between subject and object, the object meets the needs of the subject. In co-op, the mutual benefits form the cooperators, or it has no sustainable cooperation and the value itself. The co-op has complex system among cooperators, but educating is its essence. Focusing on the talents is required by the university task and the development of employer's unit. Educating is the core vale of co-op, it embodies in three points of value: personal improvement of overall quality, promotion of academic performance and career development. The achievement of educational value depends on various factors including learning opportunities provided by co-op employers, the students' commitment and ability to learn, and the commitment of staff's support in university.

\section{A. Personal Improvement of Overall Quality}

The personal improvement of overall quality including knowledge, ability, skill, method, feeling, attitude, morality and other elements which is the basic standard as a talent. The value of co-op exists in its ability to provide a transition from school to work and its flexibility to respond to industries' needs and individuals' training needs. ${ }^{[4]}$ The work experience, situation, interaction and cooperation in co-op provide learning opportunities for students, which is helpful to knowledge acquisition and ability transformation and is helpful to cultivate innovative quality and spirit, therefore the personal improvement of overall quality can be achieved.

1) Knowledge acquisition and ability transformation

Knowledge is divided into explicit knowledge and tacit knowledge by Michael Polanyi, the former can be expressed by language and words, but the latter influences our behavior and is always unconscious that is recognized by our organic approach and intuition not our reasoning process. The tacit 
knowledge can not be obtained by class study in books, the students have to obtain it by practical learning. It is just like a man who wants to learn to swim in river, the rules of swimming can be mastered by theoretical study, you have to experience it in river if you want to go swimming. We have to practice in workplace to gain the ability of problem analysis and solving, planning and communication and the cooperation with others, especially for the skills of operation. Ability transformation needs practice. The effectiveness of co-op was examined by investigation from co-op students after graduation by Tong Guofeng at a technological college of China, the co-op graduates have the best performance in operation and job skills compared with students who did not participate in co-op at that time. ${ }^{[5]}$ So the effective learning exists in practical learning environment under the learn's active learning in the pursuit of personal survival and development. The co-op is a distinct educational model that blends traditional classroom and laboratory preparation with industry based work experience, it puts the theory into practice and provides the real situation interacting with the actual producing scene experienced by students themselves to perceive problems in the process of goods production of industry. The students master practical skills by work and transform the theoretical knowledge into personal ability.

\section{2) Cultivation of feeling and attitude}

The experience is considered as the practical process in person. Learning from experience is a process of sustainable observation and practice by changing of feeling and behavior and then to obtain some knowledge form this process, mastering some skills and forming certain habits and even the formation of attitudes and behavior. The co-op provides learning opportunities outside campus to have the social experience, to have the endurance form life suffering. The co-op students perceive the culture of enterprise and observe the whole process of conducts production, workers' life and the management of company in person, these activities are useful to cultivate their work attitudes, work worship and work spirit. Work-based learning help students master the professional skill. The experiences of the activities cultivate students with work ethic, social responsibility, credit quality and cooperative spirit. ${ }^{[6]}$

3) Cultivation of innovative ability and spirit

Cultivation of innovative talents is influenced by many factors especially for the environment and platform. The society provides innovative class for co-op students in market economy. The traditional higher education model for training talents lacks of real situation, so the innovative thinking is limited and the potential ability can not be developed well. Co-op provides more practical space, more opportunities for performance and expression. The learning contents are close to society, helping to open version, extend thinking way and stimulate interest, collaborating with learning, thinking and action, helping to cultivate innovative talents. The ability of solving problems is transformed into theoretical study, which stimulates the innovation and explores new potential ability.

The scholars in western countries examined the vale of co-op by investigation or test for the improvement of personal quality. Co-op students have profound knowledge, good adaption to work post, good language expression and application, responsibility and activity, proper selforientation and higher personal quality, their performances are qualified and praised by employer. ${ }^{[7]}$ The co-op can also cultivate self-respect approved by the scholar's research. ${ }^{[8]}$ One research indicated that participants perceived the co-op as positive and the benefits for the students becoming more mature, increased self-esteem, better communicators and developing organizational skills. Students in Ontario were receiving school credits for their participation while in Ohio students were receiving school credits and at least the minimum wage. ${ }^{[9]}$ One study indicated that the primary advantage of co-op was work experience that had helped coop students personally as well, improving their assertiveness, independence, self-confidence and communication skills. The exposure to world of work leads many co-op students to raise their educational and occupational objectives. ${ }^{[10]}$ The above studies proves that the co-op can improve personal quality to meet the needs of social development.

\section{B. Promotion of Academic Development}

The alteration of work and learn help students have the opportunity to solve real problems in workplace, which stimulates learning positivity and interest, strengthens the learning objectives and subjectivity. Active learning increases understanding of knowledge and career aim and its development. The earning from work can afford the tuition fee and support students. The reward and the obtainment of educational resources help students finish academic study and stimulate learning interest. It is attractive and useful to decrease dropout rate. Academic performance of co-op students does not reduce though the co-op cost time. The results are well approved by Clemson University's co-op program research that co-op correlates with the general indicator of academic performance (cumulative grade point ratio at graduation), but not with the discipline-specific indicator (assigned grades in major specific classes). ${ }^{[11}$

The promotion of academic performance need the teacher's positive support and views. Engineering faculty at the six largest engineering co-op programs in the United States were surveyed to assess their views concerning the academic value of co-op. While expressing positive feelings about the academic value of co-op for students and to student contributions to the classroom-teaching environment, faculty utilization of classroom integration activities was extremely limited. ${ }^{[12]}$ The above prove co-op is useful to promote academic progress. The knowledge the students obtain by practice can be shifted into inner quality and intensify cognition of society under the combination of learning and behavior, which embodies the educational value of co-op.

\section{Promotion of Vocational Development}

The cooperative education can improve understanding of career morality and social responsibility. Participating in coop is helpful to the obtainment of work experience, determination of career goal, cultivation of professional consciousness, sense of self-efficacy, career decisionmarking, improvement of employment competitiveness and professional development, these are the bright value of co-op. 


\section{1) Improving professional ethics and spirit}

Co-op helps students fully understand talent specification of the requirement of employers and professional ethics of enterprise, feel the enterprise culture and staff's professional quality. Professional ethics relates not only each practitioner who treats career and work but also the performance of attitude and values on life. It is effective to train professional ethics in certain professional environment. The feasible way to cultivate professional ethics should combine internal education and external constraint. Inner enlightenment guides students to build up the correct outlook on life and values starting from the cultivation of good behavior and habits by model stimulation. External constraints focus on discipline to cultivate self education and self management, setting up the consciousness of self-reliance, cultivating professional spirit. Co-op combines inner education and external constraints to benefit students forming good professional ethics and spirit. Long-term practice is helpful to cultivate honesty, trustworthiness, justice, and service to the people as the main contents of the professional ethics, to cultivate good professional ideal, manner, responsibility, skill, discipline and professional spirit.

\section{2) Promotion of career decision-making}

The university educates students with high intelligence and qualified skills. Co-op has obvious marketization and occupational orientation, which provides students with real career situation to do the actual work in engineering projects for vocational training. It shortens the transitional periods from school to the choice of social career, the students will quickly adapt to the needs of social career after their graduation. Co-op helps students to set up correct career goal and decision.-making. Participation in co-op program can build up their self-efficacy. The participation of co-op results in the improvement of career maturity, yet little is known about the vocational behavior constructs that may produce these results. ${ }^{[13]}$

\section{3) Intensification of career concepts and awareness}

The co-op students engage in real work and accept the management of enterprise. They comply with the relevant career norms and rules as a quasi employee, which help he formation of career concepts and awareness. They constantly know of their special skills and interests in their work life to set up career goals and direction rationally for future career choice. Co-op is helpful to improve students' employment competitiveness, because employers think that "it is very important for any related work experience of students on hiring decision”. Co-op in university is very successful and popular as it is the fastest strategy to increase students' work experience. It is also proved to be one of the most successful education models to strengthen students' perseverance and employment ability. The co-op students had a broader understanding of what workers do and had a greater selfawareness of their own strengths and weaknesses than the non-cooperative education students, which can ease students' transitions from school to work. ${ }^{[14]}$
To sum up, co-op builds up a bridge between university and society for students and form a transition which is beneficial to improve the overall quality of students. Co-op has significant impacts on the training of practical skills, hardships, social adaptability and self confidence, which is the educational value of co-op program itself.

\section{REFERENCES}

[1] XU Jinyan, China's Cooperative Education Development, Beijing, petroleum engineering press, 2004, pp.36-175.

[2] ZHANG Lian, The Theoretical Problems of the Cooperation of Industry, School and Research and Its Practice in China, Vocational and Technical Education, 2002(10) , pp.21.

[3] CHENG Jiefan, Theory of Co-op and its Practice in China, Shanghai, Shanghai Jiao Tong university press, 2006:pp.128.

[4] Ullrich, Beatrice Clementine, Ed.D., An investigation of the traditional and nontraditional college students' perceived benefits regarding participation in the cooperative education program, Western Michigan University,1988, pp. 124.

[5] TONG Guofeng, Survey on Effectiveness of Co-op, Mechanical Engineering Research, 1998(3), pp.47-48.

[6] PENG Xian-tao, Reflections on Cooperative Education with Production, Journal of Yangtze University(Social Sciences), 2007(5), pp.127.

[7] LUO Qiulan,ect., Talents Quality Survey and Analysis of Co-op, Journal of Market Modernization, 2007(10), pp. 228-229.

[8] Raelin,Joe; Reisberg, Rachelle; Whitman, David; Hamann, Jerry, Cooperative education as a means to enhance self-efficacy among sophomores in undergraduate engineering from Frontiers in Education Conference Global Engineering: Knowledge without Borders Opportunities without Passports (FIE),37th Annual,2007.

[9] Young, Roy Henry, Ph.D., A case study of secondary school cooperative education programs in the province of Ontario and the state of Ohio.The Ohio State University,1995, pp. 173.

[10] Gittens,Eleanor Rogers, Ph.D., Student perceptions of the Effects of the Cooperative Education Curriculum at Fiorello $\mathrm{H}$. Laguardia Community College, Fordham University,1987, pp. 144.

[11] Burton, O'Neil B., Ph.D.,The impact of participation in a cooperative education program on the academic performance of certain engineering students at Clemson University, Clemson University, 2000, pp. 102.

[12] Scott William Kramer. A Comparative Analysis of Academic Achievement between Cooperative and Non-Cooperative Education Students within the Building Science Program at Auburn University, a Thesis Submitted to the Faculty of University, Doctor of Philosophy, May, 2003.

[13] DeLorenzo, David R., Ph.D.,The relationship of cooperative education exposure to career decision-making self-efficacy and career locus of control, Virginia Polytechnic Institute and State University, 1998, pp.122.

[14] Emenike, Hyginus Echefu, Ed. D., Rutgers, Career concepts and selfawareness due to university cooperative education by The State University of New Jersey, 1994, pp.141. 